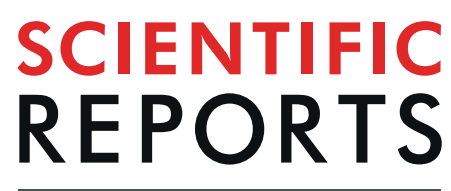

\title{
OPEN Linking flow-stream variability to grain size distribution of suspended sediment from a satellite-based analysis of the Tiber River plume (Tyrrhenian Sea)
}

\author{
J. Pitarch ${ }^{1,2}$, F. Falcini2 ${ }^{*}$, W. Nardin ${ }^{3}$, V. E. Brando ${ }^{2}$, A. Di Cicco ${ }^{2}$ \& S. Marullo ${ }^{2,4}$
}

Several coastal regions on Earth have been increasingly affected by intense, often catastrophic, flash floods that deliver significant amounts of sediment along shorelines. One of the critical questions related to the impact of these impulsive runoffs is "are flash floods more efficient in delivering noncohesive sandy sediment along the coasts?" Here we relate flow stages (i.e., from erratic to persistent) to the grain size distribution of the suspended load, by performing a synergic analysis of in-situ river discharge and satellite-retrieved grain size distribution, from 2002 to 2014, covering the 2012 Tiber River (Italy) exceptional flood event. Our analysis shows novel and promising results regarding the capability of remote sensing in characterizing suspended sediment in terms of grain size distribution and reveals that erratic stages favour delivering of non-cohesive sandy sediment more than the persistent stages. This conclusion is supported by numerical simulations and is consistent with previous studies on suspended sediment rating curves.

The hydrologic regime of the Tiber River basin (central Italy; Fig. 1a) plays an important role in sediment transport and, in turn, in the evaluation of medium- and long-term changes of the Mediterranean coastline of central Italy, called Laurentine Shore by the Romans ${ }^{1,2}$. The Tiber River is the second largest river in Italy, with a length of $409 \mathrm{~km}$ and a drainage basin of about $17.156 \mathrm{~km}^{2}$; it is sourced from Central Apennines and debouches in the Tyrrhenian Sea, close to the city of Rome. Mean annual discharge of the Tiber River is about $225 \mathrm{~m} 3 / \mathrm{s}$; maximum annual discharge exceeds $1500 \mathrm{~m}^{3} / \mathrm{s}$ and the minimum annual discharge reaches $60 \mathrm{~m}^{3} / \mathrm{s}\left(\mathrm{ref}^{3}\right)$.

The Tiber River Delta is a progradating, wave dominated system, marked by a complex cusp made up of two distributary channels (Fig. 1). The last progradation cycle (still ongoing) has particularly intensified over the last 500 years and isolated the Roman Empire harbors from the sea ${ }^{2}$. Solid transport of the Tiber River is largely given by suspended load and only a small fraction by bed load ${ }^{4}$. In particular, the percentage of sediment load transported in suspension is more than $90 \%$ of the total amount of sediment load ${ }^{3,5}$. The average annual specific sediment load, measured from 1934 to 1973 at Ripetta Bridge, located in downtown Rome (43 km upstream the river mouth; Fig. 1), is about 290 ton $/ \mathrm{km}^{2}$.

In November 2012, an exceptional flood brought the water discharge of the Tiber River to dangerous levels and it lasted from 13 to 15 November 2012 (ref. $^{6}$ ) (Fig. 1). The flood wave was originated from the exceptional river water flow due to the relevant precipitation in the upper part of the Tiber basin, which caused a significant water level rising between the November $14^{\text {th }}$ afternoon and $15^{\text {th }}$ morning in the lower part of the basin (Fig. 1). Several rain gauges recorded an abundant precipitation, higher than $300 \mathrm{~mm} / 48$ hours, in the upper and western Tiber watershed (Fig. 1). In the following days, a flood event propagated along the Tiber River main stream flow, reaching a peak in water discharge of $1,933 \mathrm{~m}^{3} / \mathrm{s}$ on November $15^{\text {th }}$ at $01: 00 \mathrm{am}$ (local time) at the water gauge station of Ripetta Bridge (Fig. 1). Floods like the one occurred in 2012 give us the opportunity to focus on

${ }^{1} \mathrm{NIOZ}$ - Royal Netherlands Institute for Sea Research, Department of Coastal Systems, and Utrecht University, PO Box 59, 1790 AB, Den Burg, Texel, The Netherlands. ${ }^{2}$ CNR - Institute of Marine Sciences (ISMAR), Via Fosso del Cavaliere 100, 00133, Rome, Italy. ${ }^{3}$ Horn Point Laboratory, University of Maryland Center for Environmental Science, Cambridge, MD, 21613, USA. ${ }^{4} E N E A$ - Centro Ricerche Frascati, Frascati, Italy. *email: federico.falcini@cnr.it 

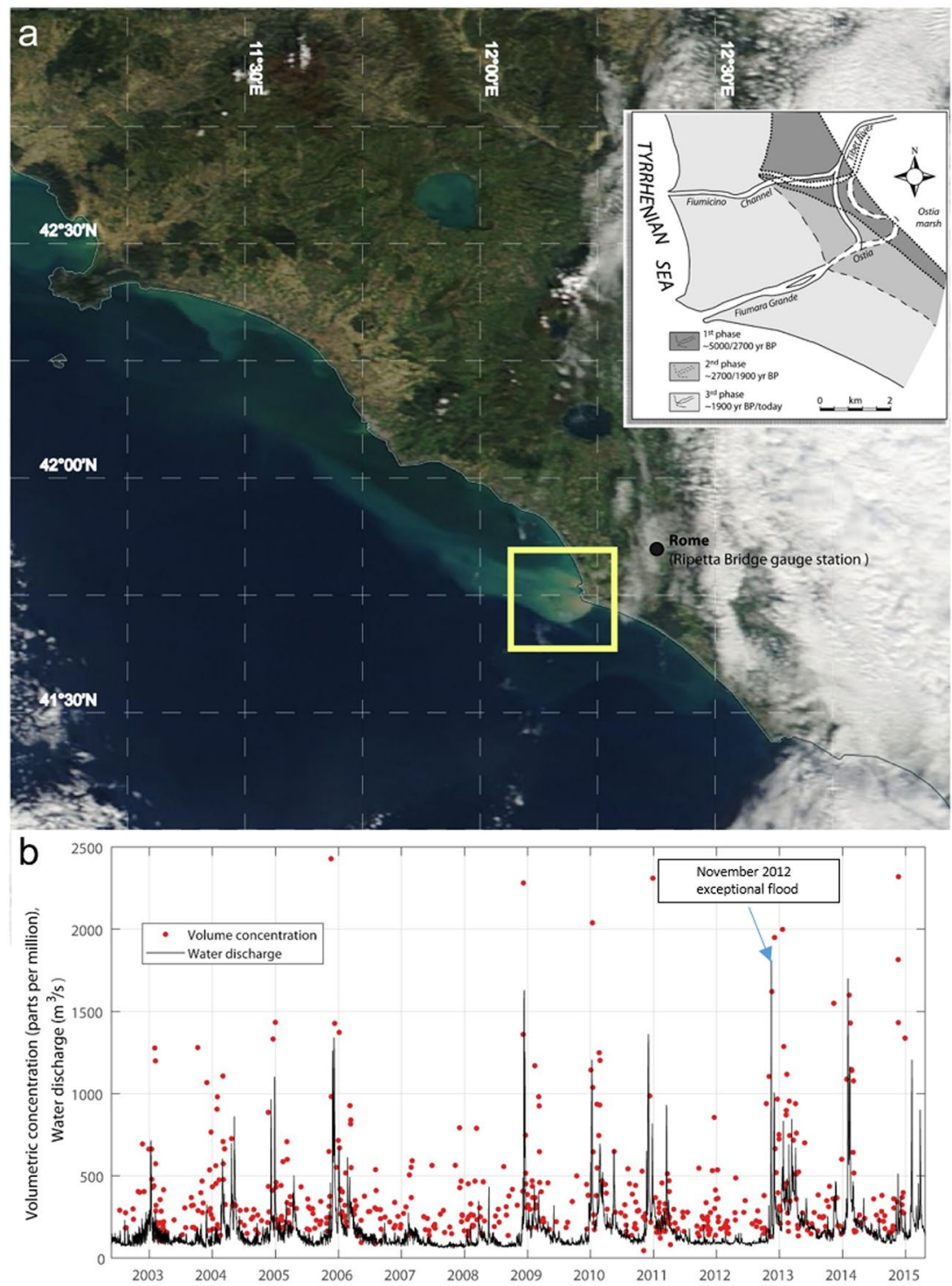

Figure 1. (a) MODIS Ocean Colour image on 17 November 2012 showing the suspended sediment plume; the yellow box around the Tiber River mouth represents the area where reflectances (Rrs) were extracted; the box shows the Tiber river delta evolution ${ }^{2}$. The image was created using data downloaded from the NASA (oceancolor.gsfc.nasa.gov) and processed using SeaDAS 7.2 (ref. ${ }^{55}$ ); (b) $\mathrm{Q}_{w}$ and the total volume concentration of suspended particles $\left(V C_{\text {tot }}\right)$ time series (plot generated by using MATLAB 7.1 http://uk.mathworks.com/ products/matlab); $V C_{\text {tot }}$ is obtained from the sum of the two volume concentrations of the grain fractions considered in this work, i.e., $3.9 \mu \mathrm{m}-62.5 \mu \mathrm{m}$ and $62.5 \mu \mathrm{m}-125 \mu \mathrm{m}$.

amount and characteristics of the suspended load delivered from erratic events in respect to water discharge and its seasonality.

Inspired by the 2012 Tiber River flood, here we seek to quantify the impact of stream flow variability, i.e., erratic vs. persistent flow stages ${ }^{7}$, on river plume sediment assemblage, by the analysis of grain size distribution (GSD) of the suspended sediment, retrieved from satellite. Grain size plays a fundamental role in settling velocity and dispersal of suspended sediment over shelf areas ${ }^{8,9}$. Observations showed that formation of sedimentary bottom layers and their related sandy and/or mud deposits strongly depends on sediment (sand, silty and/or clayey particles) settling properties ${ }^{10-13}$. In particular, the role of sediment cohesion, which is controlled by sediment size, influences morphology of deltas and coastal areas ${ }^{14}$.

Although the knowledge of sediment characteristics gives a substantial contribution in understanding and modeling particle dynamics and coastal geomorphology, GSD of suspended particles from river plumes are still seldom quantified and insufficiently documented. Satellite data can be used as an alternative technique ${ }^{15}$, in particular, off river mouth and estuarine environments, where remote sensing algorithms can be applied to mid-resolution ocean color sensors (e.g., MERIS, MODIS, SeaWiFS, VIIRS, and OLCI) that provide near-daily data at $\sim 1 \mathrm{~km}$ spatial resolution since two decades. Moreover, remote sensing has the additional advantages of providing a synoptic view of river plumes ${ }^{16-20}$. Application of $i n$-situ calibrated MODIS satellite data, for instance, 
allowed capturing the spatio-temporal variability of the distribution of suspended sediment over the coral reefs ${ }^{21}$ and assessed the impact of these extreme outflows on wetland sedimentation during the historic 2011 Mississippi River flood ${ }^{18}$.

The relationship between the spectral beam attenuation coefficient $\left(c_{p}\right)$ and the GSD has been predicted theoretically and verified experimentally by many studies ${ }^{22-24}$. However, those findings had no application to remote sensing data since the beam attenuation coefficient is not retrievable from space. Fortunately, after commercial optical backscattering meters became available, research provided evidence that the spectral particle backscattering coefficient $\left(b_{b p}\right)$ and the GSD are also related ${ }^{15,25-28}$ in a very similar fashion as $c_{p}$ and the GSD were found to be related. The advantages of this finding are many because $b_{b p}$ can be retrieved from ocean color observations, thus establishing a link between remote sensing measurements and the spatio-temporal variability of particle assemblage (i.e., the more or less large grain size fraction) for fluvial geomorphology applications and, in particular, for understanding and monitoring fate and distribution of riverine suspended load characteristics. All this sets the base for our investigation on flow-stream variability and GSD of suspended sediment from a satellite-based analysis off the Tiber River mouth.

\section{Data and Methods}

In situ hydrological data. Along the Tiber River, the water level is measured at several river flow gauges combining water level and empirical river discharge. In this work we use Tiber River daily water discharge $\left(Q_{w}\right)$ data at the historic Ripetta flow gauge, matching the period of satellite observations. Ripetta's station (http://www. idrografico.roma.it), has one of the most complete measurements data set monitoring the river discharge relative at more than $96 \%$ of the Tiber River drainage basin. To estimate the streamflow variability we then calculate monthly averages from the daily dataset, as well as the coefficient of variation of streamflow, $C V=\frac{\sigma_{Q_{w}}}{\overline{Q_{w}}}$, where $\overline{Q_{w}}$ is the flow discharge monthly mean and ${ }^{\sigma_{\mathrm{Q} w}}$ its standard deviation ${ }^{18}$; low (high) $C V$ indicates flow regimes that are weakly (highly) variable around the mean and are termed as persistent (erratic). The use of monthly averages allows us to highlight the link between GSD of suspended sediment off the river mouth and the streamflow variability ${ }^{7}$. From the comparison between daily water discharge and $C V$ (see Fig. S1 in the Supplementary Information) we observe that the coefficient of variation marks, properly, those months that were characterized by strong variability (i.e., erratic flows).

Remote estimation of the backscattering coefficient. Light back-scattered by marine particles depends on size distribution, concentration, refractive index, and the detection wavelength ${ }^{28-30}$. For a poly-dispersed assembly of non-absorbing, spherical particles with a Junge-like size distribution (see Eq. 4 below), this dependency is represented by the power law approximation of the spectral particle backscattering coefficient

$$
b_{b p}(\lambda)=b_{b p}\left(\lambda_{0}\right)\left(\frac{\lambda}{\lambda_{0}}\right)^{-\eta}
$$

where $\lambda_{0}$ is a reference wavelength and $\eta$ the spectral slope (dimensionless).

Here we retrieve the $b_{b p}$ from remote-sensing reflectances $\left(R_{r s}\right)$ data, by using the quasi-analytical algorithm (QAA) (ref. ${ }^{31}$ ), an approach that was validated in a previous work for Italian coastal and open waters ${ }^{32}$. In particular, we use observations from the Moderate Resolution Imaging Spectro-radiometer (MODIS) for the period 2002 to 2014, i.e., a data record that includes the November 2012 flood event (see Text S1 in the Supplementary Information). $\mathrm{R}_{\mathrm{rs}}$ data were remapped to a $\sim 20 \times 20 \mathrm{~km} 2$ box centered around the Tiber River mouth (Fig. 1). Its size was chosen to be 2-3 times greater than the river-induced Rossby radius of deformation in order to ensure that the whole river plume bulge was considered in our analysis ${ }^{33,34}$.

The QAA parameterization was left as originally documented except for $\eta$, a parameter that is highly relevant for the GSD estimations. In particular, the default value is given by ${ }^{35}$ :

$$
\eta=2\left\{1-1.2 \exp \left[-0.9 \frac{r_{r s}(443)}{r_{r s}(555)}\right]\right\}
$$

where $r_{r s}=R_{r s} /\left(0.52+1.7 R_{r s}\right)$

Equation (2) was originally built by using in-situ $\eta$ vs. $\mathrm{r}_{\mathrm{rs}}(443) / \mathrm{r}_{\mathrm{rs}}(555)$ matchups (see below) but the data cloud was highly scattered around the mean regression curve ${ }^{31}$ (Fig. 2b), thus having little predictive value; additionally, data were mainly taken from open ocean waters. A biased estimated $\eta$ does not have a huge impact on the retrieval of absorption and its various components, which is for what the QAA is mostly used for, but here $\eta$ is crucial component of the retrieval.

Hence, to provide reliable $\eta$ estimates, we analyzed matched in-situ spectra of $\left(\mathrm{R}_{\mathrm{rs}}\right)$ and $\mathrm{b}_{\mathrm{bp}}$ at various stations, covering a wide turbidity range, belonging to two field campaigns, conducted in 2013 and 2015 across Italian seas (Fig. 2a). $b_{b p}$ was measured with an ECO-VSF3 (Wet Labs, Inc.) at the wavelengths 470, 530 and $660 \mathrm{~nm}$. From surface data, the spectral slope $(\eta)$ was calculated as the slope of the best linear fit of $b_{b p}$ against the wavelength, both log-transformed. $\mathrm{R}_{\mathrm{rs}}$ was measured using the free-profiling technique using OCR-507 radiometers (Satlantic, Inc.), at the bands 412, 443, 490, 510, 555, 665 and $863 \mathrm{~nm}$ using protocols compliant with NASA's recommendations ${ }^{32,36,37}$.

Figure $2 \mathrm{~b}$ shows the blue-to-green band ratio $\mathrm{r}_{\mathrm{rs}}(443) / \mathrm{r}_{\mathrm{rs}}(555)$ from our in-situ reflectances respect to our measured $\eta$. Data shows high scattering but also high overestimation respect to Lee's curve (Eq. 2). For this 

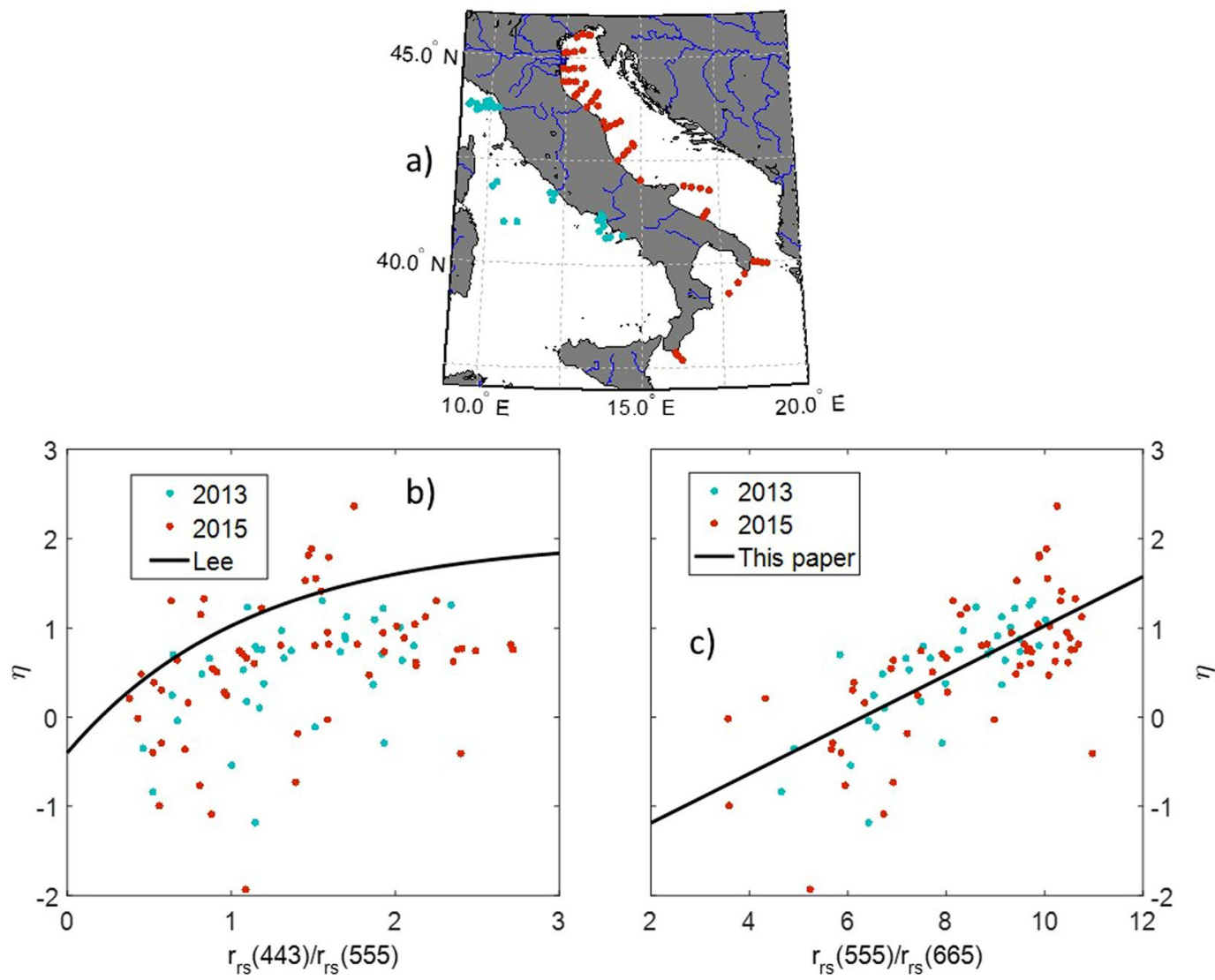

Figure 2. (a) Geographical distribution of the in situ $\mathrm{R}_{\mathrm{rs}}$ and $\mathrm{b}_{\mathrm{bp}}$ data. (b) $\mathrm{r}_{\mathrm{rs}}(443) / \mathrm{r}_{\mathrm{rs}}(555)$ vs. $\eta$ and Lee's curve (ref Lee), RMSE $=0.93 \mathrm{~m}^{-1}$. (c) $\mathrm{r}_{\mathrm{rs}}(555) / \mathrm{r}_{\mathrm{rs}}(665)$ vs. $\eta$ and the best linear fit for the data: $\eta=0.2764 \mathrm{r}_{\mathrm{rs}}(555) /$ $\mathrm{r}_{\mathrm{rs}}(665)-1.793, \mathrm{r}^{2}=0.48, \mathrm{RMSE}=0.51 \mathrm{~m}^{-1}$. Plots are generated by using MATLAB $7.1 \mathrm{http}: / /$ uk.mathworks. com/products/matlab.

reason, we choose the ratio $\mathrm{r}_{\mathrm{rs}}(555) / \mathrm{r}_{\mathrm{rs}}(665)$ as predictive variable, which results to be more sensitive to variations in coastal waters; indeed, the fit is largely improved (Fig. 2c). The best linear fit to this latter data cloud is the equation that we propose here to estimate the backscattering spectral slope from remote sensing, where we have replaced the in-situ band $665 \mathrm{~nm}$ with the MODIS band $667 \mathrm{~nm}$, assuming negligible difference between them:

$$
\eta=0.2764 \frac{r_{r s}(555)}{r_{r s}(667)}-1.7393 .
$$

GSD power law approximation. Generally, simple power law approximations of GSD (Eq. 3) can be successfully used to describe and assess poly-dispersed particle assemblies in a wide array of oceanic and estuarine water types and river plumes ${ }^{28,38}$.

$$
N(D)=N\left(D_{0}\right)\left(\frac{D}{D_{0}}\right)^{-\xi}
$$

where $D_{0}$ is a reference particle diameter and $\xi$ is a dimensionless parameter called Junge slope ${ }^{39}$. A higher $\xi$ implies a higher proportion of smaller particles and vice-versa ${ }^{40}$. $\xi$ values generally increase from river water to the open ocean ${ }^{38}$, clearly indicating that coarser particles are more confined to the near-shore areas.

The full size range can be divided in several sub-ranges to study the proportion between size classes. For instance, Kostadinov et al. (ref. ${ }^{25}$ ) applied this approach to study the particle abundance and volume in the dimensional ranges corresponding to three main phytoplankton-size classes in the global ocean ${ }^{40,41}$. Here, we consider the silt range, between the limits $3.9 \mu \mathrm{m}$ and $62.5 \mu \mathrm{m}$, and the very-fine sand range, between $62.5 \mu \mathrm{m}$ and $125 \mu \mathrm{m}$.

By assuming spherical shape, the volume concentration $(V C)$ between two given edge sizes $\left(D_{\min }, D_{\max }\right)$ is equal to:

$$
V C=\int_{D_{\min }}^{D_{\max }} N(D) \frac{4}{3} \pi\left(\frac{D}{2}\right)^{3} d D
$$


a)

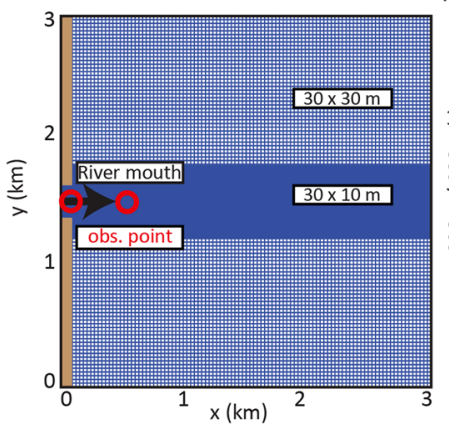

b)

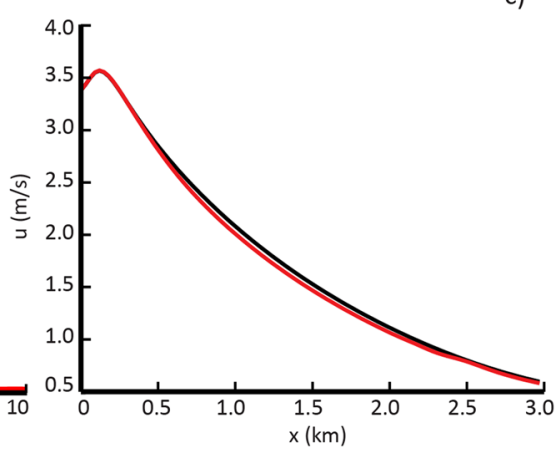

Figure 3. (a) Cells size distribution of the computational domain. Red circles show observation points position at the river mouth and $500 \mathrm{~m}$ from the river mouth. (b) Suspended sediment concentration ratio increases and then decreases during flood events. Colored lines display different duration of floods while continuous line and dashed shows, respectively, the propagation sediment at the river mouth and at the distance of $500 \mathrm{~m}$. The location of the observation points is highlighted by red circles in the panel (a). (c) Along-stream velocity profile for the two flood discharges we consider in our work: 3-day flood (blue solid line) and 10-day flood (red dashed line). The downstream transect begins from the channel mouth and is positioned at the half channel width. Plots are generated by using MATLAB 7.1 http://uk.mathworks.com/products/matlab.

$V C$ estimation can relate to a size fraction like silt $(3.9 \mu \mathrm{m}$ to $62.5 \mu \mathrm{m})$, sand $(62.5 \mu \mathrm{m}$ to $125 \mu \mathrm{m})$ or to the global assembly by taking the full size range (3.9 to $125 \mu \mathrm{m})$. In this latter case, it is named total volume concentration $\left(V C_{\text {tot }}\right)$. For these two size classes $V C_{\text {tot }}$ is equal to the sum of the particle volume of each class, reported in parts per million ${ }^{28}$.

A useful parameter, related to a GSD, is the median diameter (D50), which is the diameter at which the lower and the upper volume fractions of the GSD are equal. It is obtained after the integration of the GSD in Eq. (5), following the Junge assumption in Eq. (3):

$$
D_{50}=\left\{\begin{array}{c}
\left(\frac{D_{\max }^{4-\xi}+D_{\min }^{4-\xi}}{2}\right)^{\frac{1}{4-\xi}}, \xi \neq 4 \\
\sqrt{D_{\min } D_{\max }}, \xi=4
\end{array}\right.
$$

Remote estimation of the GSD from the backscattering coefficient. Theoretical derivations that used the Mie scattering theory ${ }^{25}$ and experimental investigation ${ }^{26,27}$ showed that the GSD can be associated to $b_{b p}$ by means of $\eta$ in Eq. (1). Such research built on previous knowledge that focused on the beam attenuation coefficient $c_{p}$ instead of on $b_{b p}$ (refs. $\left.{ }^{23,24,29}\right)$. Kostadinov et al. $\left(\right.$ ref. ${ }^{25}$ ) found that if $b_{b p}$ was predicted using Mie calculations, a relationship between $\eta$ and $\xi$ also existed, and was similar to that related to $c_{\mathrm{p}}$. Theoretical and empirical studies agree on the fact that $\xi$ increases as a monotonic function of $\eta$ and thus, as for $\xi$, lower $\eta$ is associated to a higher proportion of large particles and vice-versa.

In this work, we use the look-up table (LUT) provided by Kostadinov et al. (ref. ${ }^{25}$ ). The LUT requires the input of the spectral $b_{b p}$, which is estimated with the QAA. The LUT returns the Junge slope $\xi$, and also the GSD value $\mathrm{N}_{0}$ at a reference size $\mathrm{D}_{0}$, which is relevant for $V C_{\text {tot }}$ calculations. In this regard, we notice that $V C_{\text {tot }}$ is a concentration value of particles within a given size range, but is conceptually and methodologically different than the usual suspended particulate matter concentration which is commonly retrieved by using remote sensing techniques and expressed in mass density units (e.g. $\left.{ }^{42-44}\right)$.

Remote and hydrological data alignment. To track the river's turbid water off the river mouth from satellite-based images, we select the maximum $\mathrm{R}_{\mathrm{rs}}(667)$ value within the box for each day (Fig. 1a). In the practical implementation, we chose the sampled pixel as the closest to the 99.5 th percentile instead of the maximum to avoid outliers due to inaccuracies in pixel flagging, usually along the coastline or close to clouds. We thus obtained a time series of daily $\mathrm{R}_{\mathrm{rs}}$ spectra (at 443,488, 555 and $667 \mathrm{~nm}$ ) over the same period of the collected water discharge data. From this daily time series, daily time series of $\eta$ and the GSD were obtained and then monthly averaged.

Numerical experiments. We model river mouth sediment dynamics with Delft $3 \mathrm{D}^{45,46}$, by using different flood discharge evolution. In particular, we test consistencies between a model of sediment transport based on remote sensing observations, and a generic numerical model of sediment transport, by exploring the relation between GSD and stages (erratic vs. persistent) of river outflows (Fig. 3). Delft 3D simulates fluid flow, waves, sediment transport, and morphological changes at different timescales. The equations of fluid, sediment transport and deposition are discretized on a 3D curvilinear finite difference grid and solved by an alternating direction 
implicit scheme. Here we use the three-dimensional formulation of the hydrodynamic and sediment transport models, implemented in Delft 3D.

Delft 3D solves the Navier-Stokes equations for an incompressible fluid with the assumptions of shallow water, Boussinesq, and hydrostatic approximation. The standard $k-\varepsilon$ closure $_{\text {mode }}{ }^{47}$ is used for the vertical eddy viscosity, and the horizontal eddy viscosity is computed with a large eddy simulation technique. Transport of suspended sediment is calculated by solving the three-dimensional Advection-Diffusion equation, computed by following the method of Van Rijn ${ }^{48}$.

For our simulation, the numerical domain is a square $(3 \mathrm{~km} \times 3 \mathrm{~km})$, in which there is a river flow in inlet on the western side (Fig. 3a). The computational grid is composed of squared cells $(30 \mathrm{~m} \times 30 \mathrm{~m})$ but, along the centerline, a refinement occurs, where each cell size is $30 \mathrm{~m} \times 10 \mathrm{~m}$. We simulate a different flood progression with linear growth and falling limb two times, compared to the rising limb but same peak discharge, i.e., $Q_{w}=2000 \mathrm{~m}^{3} / \mathrm{s}$. For both study cases, we set up a rising discharge $Q$ and suspended sediment concentration (SSC) entering in the domain from the river mouth (Fig. 3a). We remark that even though the two flood discharge evolutions we consider in the numerical experiment are different, they are characterized by similar along-stream velocity profiles (Fig. 3c). In particular, the two velocity profiles remain identical till the first $500 \mathrm{~m}$ downstream, from the channel mouth (where the GSD analysis is performed). Moreover, we make clearer that our choice is not "coincidental": the 3-day flood and a 10-day flood were designed to demonstrate that the 'erraticity' (rather than the velocity) is responsible for the different suspended sediment GSD we observe from remote sensing.

For the simulations we consider the upper limit of very-fine sand size range (i.e., $125 \mu \mathrm{m}$ ), according to the fact that the suspended fraction recorded during the Tiber River floods ranges from clay to very fine sand (3.9-125 $\mu \mathrm{m})$ and that the non-cohesive very fine sand fraction is the most predominant one ${ }^{3,4}$. At the inlet, we impose a constant input of $0.6 \mathrm{~kg} / \mathrm{m}^{3}$ of suspended sediment concentration ${ }^{49}$. All sediment is characterized by specific density of $2,650 \mathrm{~kg} / \mathrm{m}^{3}$ and dry bed density of $1,600 \mathrm{~kg} / \mathrm{m}^{3}$. On the north, south, and eastern boundary we assigned a water elevation equal to zero (Fig. 3a) to reproduce the sea level. A trapezoidal river channel with flow depth $h=3$ $\mathrm{m}$ is incised into a non-erodible coastline, where we imposed a zero water depth and no flux boundary condition. The bottom roughness is modeled with the Chézy's formulation, using the constant Chézy coefficient value (i.e., $\left.65 \mathrm{~m}^{1 / 2} / \mathrm{s}\right)$. The initial condition of the models consists of a constant bathymetry with $5 \mathrm{~m}$ of erodible sediment on the basin bottom and a time step $\Delta t=9 \mathrm{~s}$.

\section{Results}

Correlation between water discharge $\left(Q_{w}\right)$ and the satellite-based total volume concentration of suspended particles $\left(V C_{\text {tot }}\right)$ shows a comforting agreement, i.e., $r=0.55$ (Fig. 1b); peaks of water discharge are always associated with high values of $V C_{\text {tot }}$, which ranges from 1200 to $2500 \mathrm{ppm}$. This qualitatively suggests that the remote sensing approach, along with the reflectance sampling method we implemented, is a promising tool for complementing the in situ hydrological dataset.

The synergy between remote sensing and hydrologic measurements, specifically, reveals an intriguing relationship between flow stage characteristics (i.e., flow erraticity) and the mean grain-size population. Here, we use the monthly particle backscattering spectral slope $(\eta)$ as an indicator of the GSD. By plotting the monthly $\eta$ versus the coefficient of variation $(\mathrm{CV})$ we find that $\mathrm{CV}$ and $\eta$ correlate negatively, thus suggesting that more erratic river discharges (higher $\mathrm{CV}$ ) relate to a larger proportion of large particles in suspension. On the contrary, more persistent flow discharges (i.e., low CV) are related to finer particles in suspension (Fig. 4). Although the dot cloud of this correlation is rather disperse, this general trend is highlighted by the best linear fit: for a given water discharge, grain-size of the suspended sediment will be larger if the flow is more erratic than if the flow is persistent. Moreover, focusing on seasonality, the correlation shows that erratic events occur mostly in late fall/early winter, when we observe high proportion of large particles in suspension.

To analyze consistency of our results, we evaluate the Junge slope $(\xi)$ and the median of grain-size diameters (i.e., the D50) within the plume, for the day that records the maximum concentration of suspended sediment of the whole time series off the river mouth, i.e., the flood event of 17 November 2012 (Fig. 5). It results that $\mathrm{R}_{\mathrm{rs}}(667)$, which is a good proxy for turbidity, sharply decreases with the distance from the river mouths (Fig. 5a); Fig. 5b,c refer to particle quality more than quantity, which explains why the plume extent is better delineated than in panel a). Still, particle sedimentation affects GSD within the river plume. Largest, presumably non-cohesive particles (i.e., $\mathrm{D} 50 \sim 65 \mu \mathrm{m}$ ) remain in suspension for few hundreds of meters from the two main mouths of the Tiber River, while the finest (clay and silt) fraction is delivered off shore. Therefore, within the plume, Fig. 5b,c shows how the grain size is decreasing as the distance to the coast increases.

The numerical experiment confirms the link between erraticity of the outflow and its ability to suspended higher concentration of sediment. To assess the behavior of suspended sediment in the river jet plume for different flow stage conditions, we obtain suspended sediment concentration for the entire water column, $S S C_{\mathrm{TOT}}$, and at $1 \mathrm{~m}$ below the water surface, $S S C_{1 \mathrm{~m}}$, from numerical simulations. The ratio $S S C_{1 \mathrm{~m}} / S S C_{\mathrm{TOT}}$ is assumed to represent the ability of the outflow to keep large (i.e., $125 \mu \mathrm{m}$ ) grain-size in suspension, and thus, to be comparable with the satellite-retrieved Junge slope. Numerical results show that, although reaching the same value of water discharge, and despite the fact that the two run show similar along-stream velocity profiles, the erratic event (i.e., the 3-days flood in Fig. 3b) suspends larger concentration of very fine-to-fine sediment, compared to a more persistent event (i.e., the 10-days flood). Moreover, in both study-cases the sediment concentration in the upper part of the plume increases due to the jet expansion. In fact, most of the sediment is suspended from the bottom layers, as bedload, to the top. 


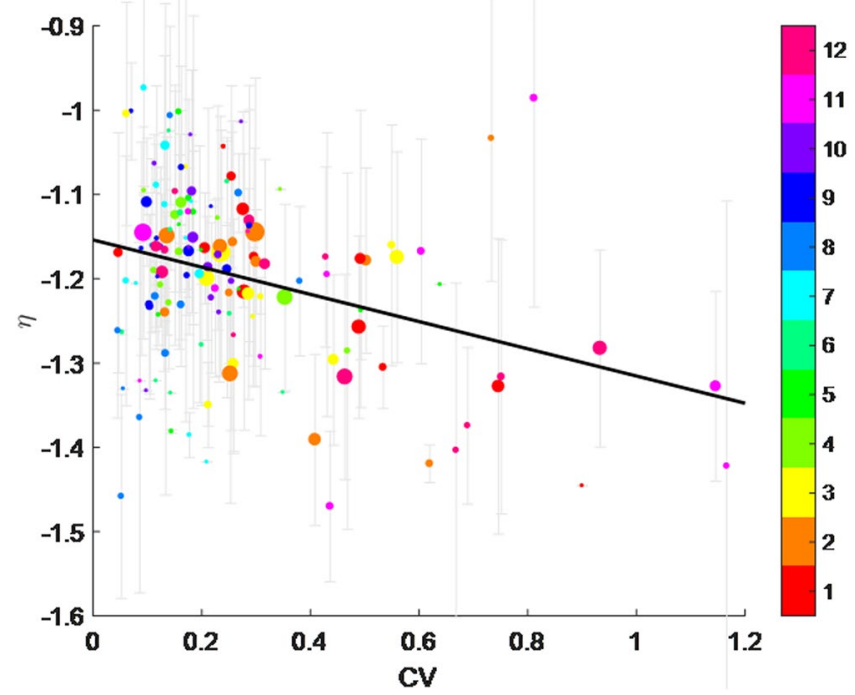

Figure 4. Scatter plot of the coefficient of variation of monthly river discharge (CV) vs. the monthly particle backscattering spectral slope $(\eta)$. Both variables are dimensionless (see text). The standard deviation of monthly $\eta$ is also indicated as vertical bars; dot diameter is proportional to the number of cloud-free satellite images. The best linear fit $\left(y=-0.186 x-1.143 ; \mathrm{r}^{2}=0.35\right)$ is meant to highlight the general trend that marks the relation between flow erraticity (CV) and GSD. Months with less than three valid observations were discarded, as calculation of a standard deviation is not possible for them. Colorbar indicates months for each point (month numbers are also reported); reddish dots represents late fall/early winter months. Plot generated by using MATLAB 7.1 http://uk.mathworks.com/products/matlab.
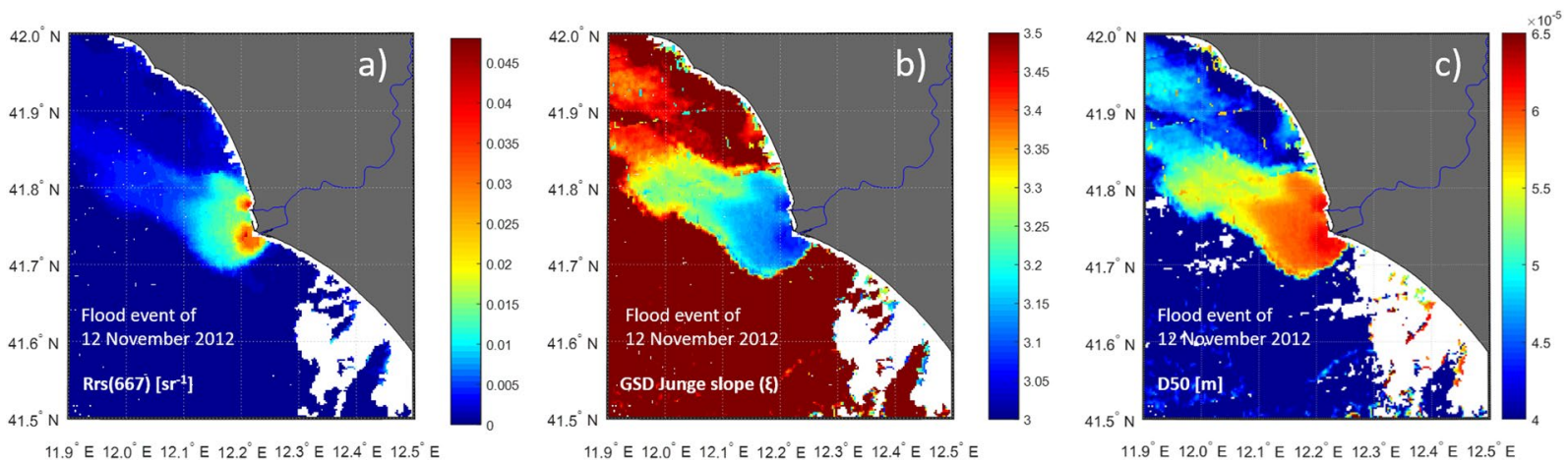

Figure 5. (a) $\operatorname{Rrs}(667)\left[\mathrm{sr}^{-1}\right]$ as a proxy for suspended sediment; (b) GSD Junge slope; (in situ) median particle diameter (D50) [m] of the GSD, after assuming a Junge slope with a minimum size of $3.9 \mu \mathrm{m}$ and a maximum of $125 \mu \mathrm{m}$, for the 12 November 2012 . The D50 [m] is analytically obtained by assuming a Junge-type GSD between the range 3.9-125 $\mu \mathrm{m}$ and it is zero out of this range. The three panels confirm that the proportion of smaller particles increases from river mouth to the open ocean and thus that coarser particles are more confined to the near-shore areas. Plots are generated by using MATLAB $7.1 \mathrm{http} / / \mathrm{uk}$.mathworks.com/products/matlab.

\section{Discussions and Conclusions}

Analysis of matched remote-sensing and in-situ hydrological data, supported by numerical simulations, showed that streamflow variability $(\mathrm{CV})$ correlates with the grain size of the suspended sediment. Accordingly, Basso et al. (ref. ${ }^{7}$ ) found that large values of coefficient of variation (CV), are associated to large values of the $\delta$-coefficient of the sediment rating curve, i.e., the power law relation between water and sediment discharges, $Q_{s}=\beta Q_{w}^{\delta}$ (where $\delta$ and $\beta$ are empirical coefficients $)^{50}$. In turn, the $\delta$-coefficient represents the erosive power of the river, with large values being indicative for rivers with a strong increase in erosive power and in sediment transport capacity when discharge increases ${ }^{38}$. Moreover, $\delta$-values are also affected by the GSD of the material available for transport, i.e. in streams characterized by sand sized sediments the power of the stream to transport sediment will be more important than in streams that mainly transport silt and clay ${ }^{51}$ (Walling et al. ${ }^{40}$ ); this will result in high $\delta$-values ${ }^{52}$.

Our results show that the synergy of remote sensing and hydrologic in situ data expands and complements these previous findings from two aspects: i) the satellite-based reconstruction of GSD (or particle backscattering 
spectral slope) time series allows for long-term statistical analyses of both water discharge and suspended sediment load, thus complementing and integrating GSD in situ measurements; ii) the synoptic property of satellite images allows for a spatial view of the sedimentary characteristics of the plume, thus helping the recognition of river plume pattern in terms of GSD. Indeed, by analyzing a ten-year-long time series, we assess the ability of unsteady flow to transport large particle size in suspension in a real field case ${ }^{53}$. Moreover, by focusing on the 2012 erratic event, we pictured depositional patterns of different grain size off the river mouth, a crucial feature that may largely impact shoreline restoration strategies ${ }^{54}$.

Previous researches demonstrated the possibility of using satellite to retrieve GSD ${ }^{24-27}$. Based on those, we retrieved a GSD long time series within the Tiber River plume off the river mouth. The resulting analysis, which paired river flow discharge data to satellite-based GSD showed i) an encouraging correlation $(r=0.55)$ between water discharge $\left(Q_{w}\right)$ and the total volume concentration $\left(V C_{\text {tot }}\right)$ of suspended particles and ii) a relationship between flow stage characteristics (i.e., flow erraticity) and the spectral slope of backscattering ( $\eta$ ), in turn, related to the GSD. Finally, by running a numerical model that confirmed what we obtained from remote sensing, therefore, assessing the relationship we find between GSD and flow variability. This, in turn, gives also robustness to our ansatz, that is, the methodology to retrieve GSD from satellite spectral slope of backscattering.

Unsteady flow makes the problem of sediment transport very complex and difficult to describe in general laws. Our work presents a novel, satellite-based tool for retrieving GSD of suspended solids debouching from river mouth, by adapting a semi-analytical technique ${ }^{25,26}$ to coastal geomorphology and sediment transport applications. From the new satellite-based tool, we find an emerging relation between GSD and flow stages (erratic vs. persistent floods), also relating this to seasonality. By setting an ad hoc numerical experiment, we then provide a mechanistic support to our findings, setting novel hypotheses on the role of sharp spatial pressure gradient (rather than shear velocity) in remobilizing sediment during river floods. This demonstrates the geomorphological effectiveness of flash floods, which are able to deliver fine-to-medium suspended load off river mouths.

Received: 28 March 2019; Accepted: 21 November 2019;

Published online: 19 December 2019

\section{References}

1. Rendell, H. M., Claridge, A. J. \& Clarke, M. L. Late Holocene Mediterranean coastal change along the Tiber Delta and Roman occupation of the Laurentine shore, central Italy. Quat. Geochronol. 2, 83-88 (2007).

2. Bellotti, P. et al. The Tiber river delta plain (central Italy): coastal evolution and implications for the ancient Ostia Roman settlement. The Holocene 21, 1105-1116 (2011).

3. Iadanza, C. \& Napolitano, F. Sediment transport time series in the Tiber River. Phys Chem Earth Parts A/B/C 31, 1212-1227 (2006).

4. Bersani P. \& Amici R. Il trasporto solido del fiume Tevere, Idrotecnica, 3, pp. 165-176 (in Italian) (1993).

5. Remedia, G. \& Alessandroni, G.M. Afflusso solido alla foce del Tevere, L'acqua, 1 (1997), pp. 43-50 (1997).

6. Costantini, S. et al. Evento Alluvionale 11-14 Novembre 2012; Regione Umbria, Servizio Protezione Civile: Perugia, Italy (2012). Available online, http://www.cfumbria.it/supporto/download/Rapportievento/02\%20Novembre\%202012/CFDUmbriaRapportoEventoNov2012. pdf (accessed on 26 March 2014).

7. Basso, S., Frascati, A., Marani, M., Schirmer, M. \& Botter, G. Climatic and landscape controls on effective discharge. Geophys. Res. Lett. 42, 8441-8447 (2015).

8. Nittrouer, C. A. et al. (Eds.). Continental margin sedimentation: From sediment transport to sequence stratigraphy (Vol. 25). John Wiley \& Sons (2009).

9. Simpson, J. H. \& Sharples, J. Introduction to the physical and biological oceanography of shelf seas. Cambridge University Press (2012).

10. Drake, D. E. Suspended sediment transport and mud deposition on continental shelves. Marine sediment transport and environmental management 40, 127-158 (1976).

11. Friedrichs, C. T. \& Wright, L. D. Gravity-driven sediment transport on the continental shelf: implications for equilibrium profiles near river mouths. Coast. Eng. 51, 795-811 (2004).

12. Falcini, F., Fagherazzi, S. \& Jerolmack, D. J. Wave-supported sediment gravity flows currents: Effects of fluid-induced pressure gradients and flow width spreading. Cont. Shelf Res. 33, 37-50 (2012).

13. Fagherazzi, S. D. A. et al. Dynamics of river mouth deposits. Rev. of Geophys. 53, 642-672 (2015).

14. Edmonds, D. A. \& Slingerland, R. L. Significant effect of sediment cohesion on delta morphology. Nat. Geosci. 3, 105 (2010).

15. Pinet, S., Martinez, J. M., Ouillon, S., Lartiges, B. \& Villar, R. E. Variability of apparent and inherent optical properties of sedimentladen waters in large river basins-lessons from in situ measurements and bio-optical modeling. Opt. express 25, A283-A310 (2017).

16. Walker, N. D. Satellite assessment of Mississippi River plume variability: causes and predictability. Remote Sens. Environ. 58, 21-35 (1996).

17. Shi, W. \& Wang, M. Satellite observations of flood-driven Mississippi River plume in the spring of 2008. Geophys. Res. Lett. 36 (2009).

18. Falcini, F. et al. Linking the historic 2011 Mississippi River flood to coastal wetland sedimentation. Nat. Geosci. 5, 803 (2012).

19. Brando, V. E. et al. High-resolution satellite turbidity and sea surface temperature observations of river plume interactions during a significant flood event. Ocean Sci. 11, 909 (2015)

20. Ouillon, S. Why and How Do We Study Sediment Transport? Focus on Coastal Zones and Ongoing Methods. Water 10, 390 (2018).

21. Restrepo, J. D., Park, E., Aquino, S. \& Latrubesse, E. M. Coral reefs chronically exposed to river sediment plumes in the southwestern Caribbean: Rosario Islands, Colombia. Sci. Total Environ. 553, 316-329 (2016).

22. Twardowski, M. S. et al. A model for estimating bulk refractive index from the optical backscattering ratio and the implications for understanding particle composition in case I and case II waters. J. Geophys. Res.: Oceans 106, 14129-14142 (2001).

23. Boss, E. et al. Spectral particulate attenuation and particle size distribution in the bottom boundary layer of a continental shelf. J. Geophys. Res.: Oceans 106, 9509-9516 (2001).

24. Boss, E., Twardowski, M. S. \& Herring, S. Shape of the particulate beam attenuation spectrum and its inversion to obtain the shape of the particulate size distribution. Appl. Optics 40, 4885-4893 (2001).

25. Kostadinov, T. S., Siegel, D. A. \& Maritorena, S. Retrieval of the particle size distribution from satellite ocean color observations. J. Geophys. Res.: Oceans 114, C09015 (2009).

26. Kostadinov, T. S., Siegel, D. A., Maritorena, S. \& Guillocheau, N. Optical assessment of particle size and composition in the Santa Barbara Channel, California. Appl. optics 51, 3171-3189 (2012).

27. Slade, W. H. \& Boss, E. Spectral attenuation and backscattering as indicators of average particle size. Appl. optics 54, 7264-7277 (2015). 
28. Many, G. et al. Particle assemblage characterization in the Rhone River ROFI. J. Marine Sys. 157, 39-51 (2016).

29. Morel, A. The scattering of light by sea water: experimental results and theoretical approach. Optics of the sea, interface and in-water transmission and imaging AGARD Lecture Series (61), 3.1.1-3.1.76 (1973).

30. Babin, M., Morel, A., Fournier-Sicre, V., Fell, F. \& Stramski, D. Light scattering properties of marine particles in coastal and open ocean waters as related to the particle mass concentration. Limnol. and Oceanogr. 48, 843-859 (2003).

31. Lee, Z., Carder, K. L. \& Arnone, R. A. Deriving inherent optical properties from water color: a multiband quasi-analytical algorithm for optically deep waters. Appl. optics 41, 5755-5772 (2002).

32. Pitarch, J., Volpe, G., Colella, S., Santoleri, R. \& Brando, V. Absorption correction and phase function shape effects on the closure of apparent optical properties. Appl. optics 55, 8618-8636 (2016).

33. Nof, D. \& Pichevin, T. The ballooning of outflows. J. Phys. Oceanogr. 31, 3045-3058 (2001).

34. Geyer, W. R., Hill, P. S. \& Kineke, G. C. The transport, transformation and dispersal of sediment by buoyant coastal flows. Cont. Shelf Res. 24, 927-949 (2004).

35. Lee, Z., Lubac, B., Werdell, J. \& Arnone, R. An Update of the Quasi-Analytical Algorithm (QAA_v5), http://www.ioccg.org/groups/ Software_OCA/QAA_v6_2014209.pdf (2014).

36. Mueller, J. L. Inherent optical properties: Instruments, characterizations, field measurements and data analysis protocols. In Ocean Optics Protocols for Satellite Ocean Color Sensor Validation; Revision 4; Volume IV; Err. 1; Mueller, J. L., Fargion, G. S., McClain, C. R., Eds. NASA Goddard Space Flight (2003).

37. Pitarch, J., Bellacicco, M., Volpe, G., Colella, S. \& Santoleri, R. Use of the quasi-analytical algorithm to retrieve backscattering from in-situ data in the Mediterranean Sea. Remote Sens. Lett. 7, 591-600 (2016).

38. Buonassissi, C. J. \& Dierssen, H. M. A regional comparison of particle size distributions and the power law approximation in oceanic and estuarine surface waters. J. Geophys. Res.: Oceans 115, C10028 (2010).

39. Junge, C. E. Air chemistry and radioactivity. 382-382 (1963).

40. Sieburth, J. M., Smetacek, V. \& Lenz, J. Pelagic ecosystem structure- Heterotrophic compartments of the plankton and their relationship to plankton size fractions. Limnol. Oceanogr. 23, 1256-1263 (1978).

41. Vidussi, F., Claustre, H., Manca, B. B., Luchetta, A. \& Marty, J. C. Phytoplankton pigment distribution in relation to upper thermocline circulation in the easternMediterranean Sea during winter. J. Geophys. Res. 106, 19939-19956 (2001).

42. D'Sa, E. J., Miller, R. L. \& McKee, B. A. Suspended particulate matter dynamics in coastal waters from ocean color: Application to the northern Gulf of Mexico. Geophys. Res. Lett. 34, L23611 (2007).

43. Nechad, B., Ruddick, K. G. \& Park, Y. Calibration and validation of a generic multisensor algorithm for mapping of total suspended matter in turbid waters. Remote Sens. Environ. 114, 854-866 (2010).

44. Dogliotti, A. I., Ruddick, K. G., Nechad, B., Doxaran, D. \& Knaeps, E. A single algorithm to retrieve turbidity from remotely-sensed data in all coastal and estuarine waters. Remote Sens. Environ. 156, 157-168 (2015).

45. Roelvink, J. A. \& Van Banning, G. K. F. M. Design and development of DELFT3D and application to coastal morphodynamics. Oceanograph. Lit. Rev. 11, 925 (1995).

46. Lesser, G. R., Roelvink, J. V., Van Kester, J. A. T. M. \& Stelling, G. S. Development and validation of a three-dimensional morphological model. Coast. Eng. 51, 883-915 (2004).

47. Rodi, W. Turbulence models and their application in hydraulics, State-of-the-art paper article sur l'etat de connaissance. IAHR Paper presented by the IAHR-Section on Fundamentals of Division II: Experimental and Mathematical Fluid Dynamics, The Netherlands (1984).

48. Van Rijn, L. C. Principles of sediment transport in rivers, estuaries and coastal seas (Vol. 1006). Amsterdam: Aqua publications (1993).

49. Nardin, W., Mariotti, G., Edmonds, D. A., Guercio, R. \& Fagherazzi, S. Growth of river mouth bars in sheltered bays in the presence of frontal waves. J. Geophys. Res.: Earth Surface 118(2), 872-886 (2013).

50. Syvitski, J. P., Morehead, M. D., Bahr, D. B. \& Mulder, T. Estimating fluvial sediment transport: the rating parameters. Water Resour. Res. 36, 2747-2760 (2000)

51. Walling, D. E. Assessing the accuracy of suspended sediment rating curves for a small basin. Water Resour. Res. 13, 531-538 (1977). 52. Asselman, N. E. M. Fitting and interpretation of sediment rating curves. J. Hydrol. 234, 228-248 (2000).

53. Mrokowska, M. M. et al. Flume experiments on gravel bed load transport in unsteady flow-preliminary results. In Hydrodynamic and Mass Transport at Freshwater Aquatic Interfaces (pp. 221-233). Springer, Cham (2016).

54. Canestrelli, A., Lanzoni, S. \& Fagherazzi, S. One-dimensional numerical modeling of the long-term morphodynamic evolution of a tidally-dominated estuary: The Lower Fly River (Papua New Guinea). Sediment. Geol. 301, 107-119 (2014).

55. https://oceancolor.gsfc.nasa.gov/data/10.5067/AQUA/MODIS/L2/OC/2018/NASA Goddard Space Flight Center, Ocean Ecology Laboratory, Ocean Biology Processing Group. Moderate-resolution Imaging Spectroradiometer (MODIS) Aqua Ocean Color Data; 2018 Reprocessing. NASA OB.DAAC, Greenbelt, MD, USA. doi: data/10.5067/AQUA/MODIS/L2/OC/2018. Accessed on $12 / 06 / 2019$.

\section{Acknowledgements}

MODIS AQUA images were provided by NASA Goddard Space Flight Center, Ocean Ecology Laboratory, Ocean Biology Processing Group; (2014): Moderate-resolution Imaging Spectroradiometer (MODIS) Aqua Ocean Color Data; 2018 Reprocessing. NASA OB.DAAC, Greenbelt, MD, USA. doi: data/10.5067/AQUA/MODIS/L2/ OC/2018. Accessed on 12/06/2019. Daily-averaged water discharge data were provided by the website http:// www.idrografico.roma.it. This work was undertaken as part of the costeLAB Project (Progetto Premiale "Rischi Naturali Indotti dalle Attività Umana - COSTE", CIG 6256318CED, n. 2017-I-E.0), funded by the Italian Space Agency. Jaime Pitarch received partial funding from the Ministry for Science and Culture of Lower Saxony, Germany through the "Coastal Ocean Darkening" project (VWZN3175). Partial support was also provided by European Marine Observation and Data network - Physics, and the Flagship Project RITMARE-The Italian Research for the Sea-coordinated by the Italian National Research Council and funded by the Italian Ministry of Education, University and Research within the National Research Program 2011-15. We finally thank D.J. Jerolmack and C. Paola for the insightful discussions at the initial stage of the work. Any use of trade, product, or firm names is for descriptive purposes only and does not imply endorsement by the Italian Government.

\section{Author contributions}

J.P. performed both remote sensing analysis and hydrographic analysis, contributed to collection and presentation of the data, contributed to the overall study, participated in data interpretation, and contributed to the writing of this manuscript. F.F. supervised the research, contributed to the data interpretation and presentation, set the main, leading hypotheses of the work, led the writing of the main text, and coordinated the overall study. S.M. and 
V.B. co-supervised the research, and participated in data interpretation. A.D. participated in data interpretation, and contributed to the remote sensing analysis. W.N. performed the numerical experiment and contributed to the overall study, participated in data interpretation, and contributed to the writing of this manuscript.

\section{Competing interests}

The authors declare no competing interests.

\section{Additional information}

Supplementary information is available for this paper at https://doi.org/10.1038/s41598-019-56409-8.

Correspondence and requests for materials should be addressed to F.F.

Reprints and permissions information is available at www.nature.com/reprints.

Publisher's note Springer Nature remains neutral with regard to jurisdictional claims in published maps and institutional affiliations.

(c) (i) Open Access This article is licensed under a Creative Commons Attribution 4.0 International License, which permits use, sharing, adaptation, distribution and reproduction in any medium or format, as long as you give appropriate credit to the original author(s) and the source, provide a link to the Creative Commons license, and indicate if changes were made. The images or other third party material in this article are included in the article's Creative Commons license, unless indicated otherwise in a credit line to the material. If material is not included in the article's Creative Commons license and your intended use is not permitted by statutory regulation or exceeds the permitted use, you will need to obtain permission directly from the copyright holder. To view a copy of this license, visit http://creativecommons.org/licenses/by/4.0/.

(c) The Author(s) 2019 